\title{
National assessment of cancer drugs commences
}

$\mathrm{W}$

hile not binding on provinces, Canada's recently created national oncology review process may already be helping to standardize cancer therapies and better inform decision-makers across the nation.

Patient advocacy groups have long expressed concern that the review process would do little to mitigate national variations in access to cancer drugs as each province retains the authority to decide whether to include the therapy under its provincial medicare plan (www.cmaj.ca/lookup /doi/10.1503/cmaj.109-3262).

But there are indications that some provinces intend to align their policies with national recommendations made by the pan-Canadian Oncology Drug Review (pCODR), says Dr. Charles Blanke, cochair of the pCODR steering committee and vice-president, systemic therapy, of the British Columbia Cancer Agency. The latter, he says, is "already modifying [their] own particular processes so they mesh better with pCODR."

pCODR, which began accepting submissions this summer, was created to provide advice to all provincial governments (except Quebec, which opted not to participate), with advice on whether to fund new cancer drugs.

In deciding whether to recommend provincial funding for a new drug, the committee examines the health benefits of the drug, including such things as clinical safety, effectiveness, burden of illness and therapeutic need of patients, says Mona Sabharwal, executive director of pCODR.

They also consider the patient perspective to "understand not just the physical, but emotional and economic impacts of cancer," she adds. Costeffectiveness is also evaluated by comparing net costs and net benefits in a systematic way. Finally, pCODR considers "the practical issues around introducing a new drug technology into the health system," such as whether a

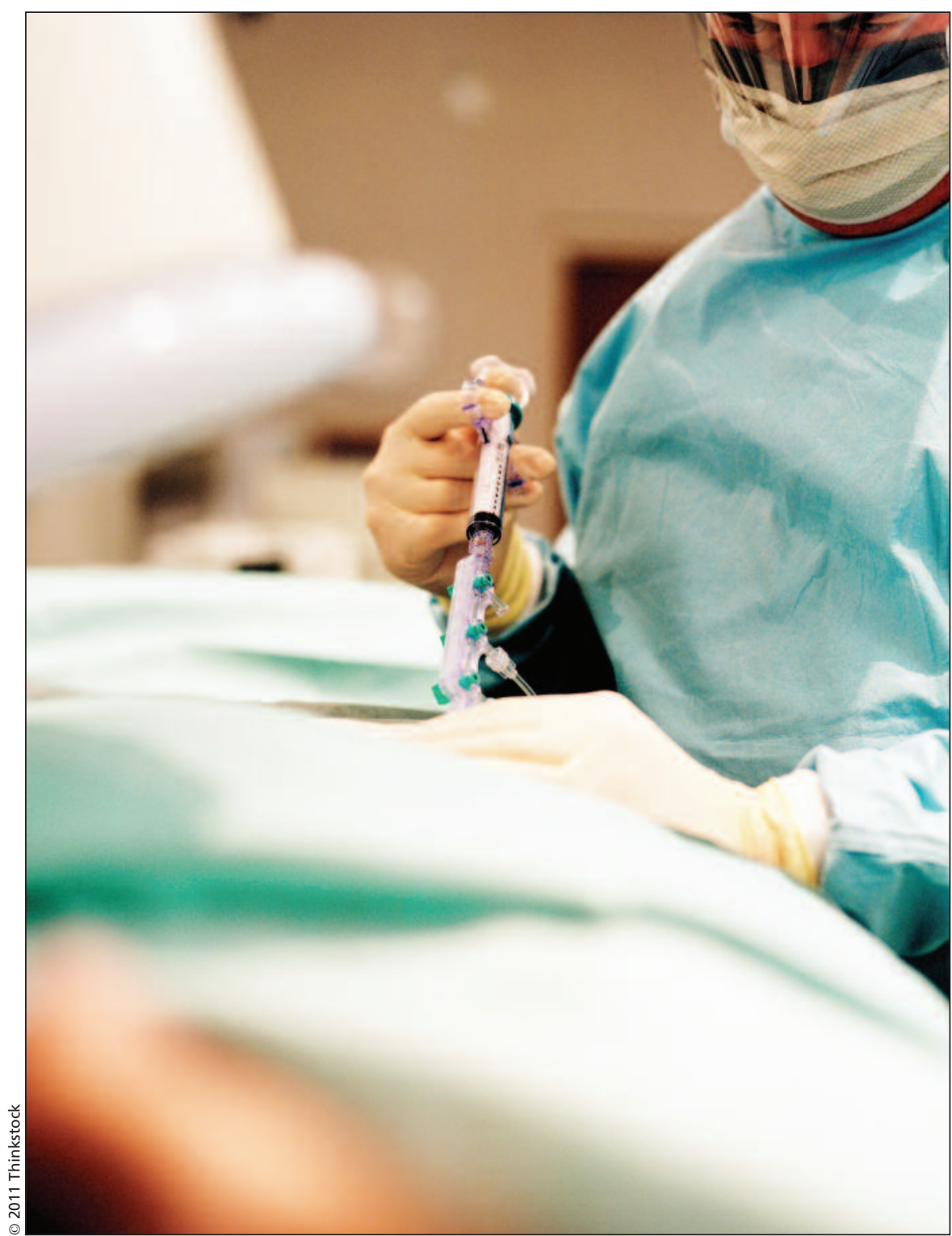

Proponents argue that national reviews will expedite the availability of the numerous, and often expensive, new cancer drugs that are coming onto the market.

specific molecular test will need to be implemented before a new therapy can be introduced.

Proponents argue that the national review process will expedite the availability of the numerous, and often expensive, new cancer drugs that are coming onto the market.

A single review body will give all provinces "additional opportunities and probably increases the chances of get- ting some of the exciting new drugs," Blanke says.

"The process is meant to reduce duplication of effort by individual provinces and cancer agencies," says Sabharwal. "I think people who make funding decisions around what they might cover for their population need to make sure that when they do pay for those therapies, it's based on good information [and] rigorous review of 
both the clinical effectiveness and costeffectiveness," she says.

Submissions can be made prior to a drug being approved for sale in Canada, which should make drugs more rapidly available in the event they are approved, Sabharwal adds.

"I think it will certainly make the process faster overall. Obviously if we wait (for market approval) there's a builtin delay that we can bypass completely," says Blanke.

Sabharwal says manufacturers will also benefit from national review as they'll have clearer expectations of standards, while clinicians will benefit from the comprehensiveness and consistency of reviews. Meanwhile, patients can "feel confident in the recommendations" because of the collaborative input of experts from across Canada, she adds.

The thoroughness of reviews will be a major benefit for clinicians, Blanke says. "There's no danger or at least markedly less danger that physicians will get inadequate information" regarding either efficacy or safety because the pCODR process is built to consider everything relevant, such as hidden trials with less positive results and clearly laid out costs.
The federal government is hopeful that the national review process will yield affordable access to cancer drugs, Health Canada spokesperson Olivia Caron writes in an email. "The Government of Canada continues to be open to discussing ways to better manage pharmaceuticals and contain costs, and thus is certainly interested in working with provincial and territorial counterparts on common approaches to the review of the clinical- and cost-effectiveness of new cancer drugs." - Erin Walkinshaw, Ottawa, Ont.

CMAJ 2011. DOI:10.1503/cmaj.109-3968 